\title{
Improving Understanding about Social Influences on Food Choices in College Students: A Pilot Study
}

\author{
Corey H. Basch ${ }^{1}$, Michele Grodner ${ }^{1} \&$ Lindsay Prewitt ${ }^{1}$ \\ ${ }^{1}$ Department of Public Health, William Paterson University, Wayne, New Jersey, USA \\ Correspondence: Corey H. Basch, Department of Public Health, University Hall 366, William Paterson \\ University, Wayne, New Jersey, 07470, USA. Tel: 973-720-2603. E-mail: baschc@wpunj.edu
}

Received: February 18, 2016

Accepted: May 10, 2016 Online Published: August 5, 2016

doi:10.5539/gjhs.v9n4p1

URL: http://dx.doi.org/10.5539/gjhs.v9n4p1

\begin{abstract}
The impact of social influences on food choices in college settings is of great importance because students are vulnerable to new forming identities at this time. The purpose of this pilot study is to determine the degree to which social influences impact food choices in a sample of college students. A 22-item survey instrument was created to determine the extent to which students have experienced being influenced by others when making food related purchasing decisions. A total of 257 out of a 323 students invited ( $80 \%$ response rate) in 11 sections of a personal health course responded to the survey. The overwhelming majority of respondents were reportedly comfortable ordering whatever they wanted when in the presence of their friends $(n=249 ; 97 \%)$. Students were more likely to feel pressure to make a healthy choice than an unhealthy choice if everyone else was $(45.1 \%$ vs. $31.5 \%)$, but fewer felt this way when asked specifically if their friends were ordering ( $28.4 \%$ vs. $21 \%)$. Social influences surrounding food choices are a topic that has gained momentum recently, however more research needs to be conducted to determine the reasons why social influences affect certain college students especially in comparing healthy versus unhealthy food choices.
\end{abstract}

Keywords: college students, social influences, food choices

\section{Introduction}

Eating in the company of others alters the experience in varied ways. For instance, it has a significant impact on the amount of food one consumes when compared to eating alone (de Castro \& de Castro, 1989). Often times, these results in a change in meal size and consumption, but the impact of social influence on eating vary. There is a range of literature on this topic in terms of differing ages and study designs. Regardless of the variations, adherence to social norms is all in an attempt to be liked by peers and avoid any punishment, stigma, or embarrassment that may come from being an outlier (Higgs, 2014).

One study indicated that all meals eaten alone contained fewer calories, carbohydrates, fat, and protein than when meals were eaten with others (de Castro \& de Castro, 1989). Deprivation ratios were smaller and satiety ratios were greater when eating with others than for meals eaten alone (de Castro \& de Castro, 1989). The more people present at mealtime lead to larger amounts of food ingested. These findings were confirmed in a recent meta-analysis. The reviewed studies provided information about eating habits of others to determine if it influenced food choices. The meta-analysis concluded that social norms influenced food choices in terms of high or low caloric intake (Robinson, Thomas, Aveyard, \& Higgs, 2014).

Another study focused on adults and how their types of relationships create social facilitation related to food intake. Results revealed that the companion an individual eats with significantly impacts the way in which one consumes food. Meals eaten with a spouse, family, friend, co-worker and others were bigger proportionately than those eaten alone (de Castro, 1994). Specifically, meals eaten with friends were larger and eaten over a longer time (de Castro, 1994). Along similar lines, a study conducted in a fast food restaurant environment found that females ate fewer calories in a mixed sex group when compared to a same sex group. Thus suggesting that gender is an influential force as well (Brindal, Wilson, Mohr, \& Wittert, 2015).

Attention to the role of social influence and obesity has been considered through several factors. Christakis and Fowl studied the offspring cohort (and people to whom they are linked) from the Framingham Heart Study to determine how the spread of obesity moves through social networks. Highlights of the results include an 
increased chance of becoming obese in a given interval if a spouse, friend, sibling, or mutual friend becomes obese (Christakis \& Fowler, 2007). It is interesting to note that there was no association between neighbors; meaning that environmental proximity does not necessarily matter, however social closeness or social proximity appears to be a factor.

The main goal of a study on the effects of social networks on eating behaviors examined the associations between Australian adolescents' friendships (social network) with high-calorie consumption, physical activity, and sedentary screen-based behaviors. In addition, social popularity of these adolescents was considered (De La Haye, Robins, Mohr, \& Wilson, 2010). Results indicate that for two of the three friendship networks studied, physical activity was an important factor among friendships (De La Haye, Robins, Mohr, \& Wilson, 2010). Furthermore, findings indicate that select obesity related behaviors tended to be associated with popularity (De La Haye, Robins, Mohr, \& Wilson, 2010).

Valente and colleagues aimed to determine if overweight adolescents were more or less likely to have overweight friends (Valente, Fujimoto, Chou, \& Spruijt-Metz, 2009). In this study, being overweight was more common with certain demographic characteristics, including a friend's average BMI (Valente, Fujimoto, Chou, \& Spruijt-Metz, 2009). In concert with conclusions of other studies, students who were of a similar weight stature were more likely to be friends (Valente, Fujimoto, Chou, \& Spruijt-Metz, 2009).

In an interesting study, data from the National Longitudinal Study of Adolescents Health was used to determine that a person's relative weight status is a significant predictor of that person's perceived weight status (Marathe, Pan, \& Apolloni, 2013). Generally speaking, the larger a person was, the fewer the amount of friends they had, however this was not necessarily the case across all races or nationalities (Marathe, Pan, \& Apolloni, 2013). The relationship between social influence, dietary intake patterns and weight status requires additional exploration.

Consideration of an individual's awareness of social influence while eating and how this awareness affects matching or mimicking behaviors was the focus of another study (Spanos, Vartanian, Herman \& Polivy, 2014). Results show highly social eaters were more likely to mimic behaviors and also more likely to report noticing social influences than less social eaters (Spanos, Vartanian, Herman \& Polivy, 2014).

A similar study was conducted to ascertain if individuals were aware of social influences on their food choices. In this study, participants were given information about prior eating choices of others to observe if this knowledge influenced participants own food choices (Robinson \& Field, 2015). Of the participants, more reported not being affected by social influences (56 \%) while reporters of social influences were $34 \%$. Ten percent were unsure (Robinson \& Field, 2015).

A meta-analysis of 38 articles related to modeling behavior and food intake found a large impact $(\mathrm{r}=.39)$, and highlighted the fact that inhibitory model effects were greater. This implies that when models inhibited the amount of food they ate their peers' limited intake. Although the same was seen when models raised the bar and the peers ate freely, the effects were greater in the inhibitory studies (Vartanian, Spanos, Herman \& Polivy, 2015).

A study of adolescents (aged 16-19 years) considered the relationship between perceived norms and dietary behaviors. Findings revealed that the adolescents, when questioned about habits of their peers underestimated their consumption of healthy foods including fruits and vegetable and overestimated intakes of unhealthy foods including sugary beverages and snacks. Social norm misperceptions such as these generate an environment of tolerance of unhealthy foods. Interventions addressing these misperceptions may limit their impact on food choices (Lally, Bartle \& Wardle, 2011).

Studies on small samples of college students exist in the literature, but tend to be controlled experiments looking at high and low caloric intake as a reaction to a cue such as an informational flyer (Robinson, Fleming, \& Higgs, 2014), papers (Berger \& Rand, 2008; Berger \& Heath, 2008) or information about what others ate (Yamasaki, Midzuno, \& Aoyam, 2007).

A recent study focused on healthy and unhealthy social norms in which a portion of college students were exposed to a sign indicating one of three norms (healthy descriptive norm, unhealthy descriptive norm, or a healthy injunctive norm) and compared with controls. The major finding in this study was that, compared to unhealthy descriptive norms, healthy descriptive norms were more likely to yield an outcome of making healthy food choices. Given that this study took place on campus in a food court, this suggests that positive messaging could be influential (Mollen, Rimal, Ruiter, \& Kok, 2013).

Consideration of barriers limiting healthy eating is a significant approach for creation of interventions to support healthy food choices. Psychological factors related to dietary choices such as self-efficacy and behavior control 
should be addressed in future interventions (Hardcastle, Thogersen-Ntoumani, \& Chatzisarantis, 2015). Social influences on food choices may be a significant psychological factor for students in college settings because students are vulnerable to forming new identities at this time. The purpose of this pilot study was to determine the degree to which social influences impact food choices in a sample of college students.

\section{Methods}

A 22-item survey instrument was created to determine the extent to which students have experienced being influenced by others when making food related purchasing decisions. The questions on the survey were based on 1) Demographics (6 questions); 2) Thoughts and experiences making food choices (5 questions); 3) Level of agreement with statements regarding personal food choices (5 questions); 4) Frequency with which the respondent feels pressure in making personal food choices (6 questions).

Demographics included the following areas: age; gender; class year; age; major; and current living situation.

Thoughts and experiences making food choices included the following questions:

How do you define healthy food choices?

Which setting are college students most likely to make healthy food choices?

If a friend were to order a healthy meal what kind of experience would they face?

In a typical week, how many times do you go out to eat with friends?

When out to eat with friends, have you ever been made fun of for your food choices?

If yes, did that lead you to order differently the next time you went out with your peers?

Level of agreement with statements regarding personal food choices included the following questions:

When I am out with my friends I feel comfortable ordering anything I want to eat.

I feel pressure to make healthy choices when everyone else is.

I feel pressure to make unhealthy choices when everyone else is.

I won't choose a healthy option for fear of what my friends will say to me.

I won't choose an unhealthy option for fear of what my friends will say to me.

Frequency with which the respondent feels pressure in making personal food choices included the following questions:

How often do you feel pressure in a group setting to order like everyone else?

How often do you feel pressure to make unhealthy food choices when your social group is?

How often do you feel pressure to make healthy food choices when your social group is?

How often do you feel that your peers have led you to order or eat food that you did not really want?

How often have you ordered something you did not want because you thought it was the more acceptable option?

How often do you feel pressure in a group setting, to eat as much your peers?

The items were created based on current literature, through interactions with students regarding this topic, and classroom discussions in select public health courses. An email invitation was sent to all instructors of 13 in-person sections of a personal health course delivered in person during the spring semester of 2015 to invite their students to participate in this project. Two instructors declined the invitation, and 11 accepted. In the sections of this course where instructors accepted, surveys were distributed for all students in the class with a total of 323 invited students. The response rate was $80 \%$ as 257 of surveys were returned. Responses were anonymous and participants were offered the chance to win a $\$ 25.00$ gift card to a music service by writing their email address on a separate sheet of paper to maintain anonymity. Descriptive statistics, including frequencies, percentages, and means, ranges, and standard deviations were calculated using SPSS (version 21). Additionally, independent sample t-tests were used to compare differences in responses. This study was approved by the Institutional Review Board at William Paterson University.

\section{Results}

\subsection{Demographics}

Demographic characteristics of the participants are described below. The majority of participants were female 
$(58 \% ; n=149)$ and were freshman in college ( $42 \% ; n=108)$. The mean age of participants was 20.2 years of age (SD 2.5). Additionally, the majority of respondents were not in a health related major $(80.5 \% ; n=207)$ and were commuters to the university campus $(63 \% ; \mathrm{n}=161)$.

\subsection{Thoughts and Experiences Making Food Choices}

The most common definition for healthy eating was an appropriate balance of nutrients $(n=202 ; 78.6 \%)$, followed by wholesome foods rather than processed foods $(\mathrm{n}=101 ; 39.3 \%)$, the least common were what makes you happy $(\mathrm{n}=60 ; 23.3 \%)$, what's available $(\mathrm{n}=40 ; 15.6)$ and other $(\mathrm{n}=9 ; 3.5 \%)$. The setting whereby students felt healthiest choices would be made was with family (not in combination with any other setting) $(\mathrm{n}=101$; $39.9 \%)$ or by themselves $(n=80 ; 31.1 \%)$. Eating with their friends was a less frequent choice $(n=37 ; 14.4 \%)$ as were combinations of these three settings. When asked what a typical reaction would be if a friend were to order a healthy meal, the most common response was no comment $(\mathrm{n}=103 ; 40.1 \%)$ followed by teasing $(\mathrm{n}=98 ; 38.1 \%)$, praise $(\mathrm{n}=73 ; 28.4 \%)$, and other $(\mathrm{n}=2 ; .8 \%)$. The mean number of times eating out in a typical week was 2.4 (SD 2.2; range $0-15)$. A total of 61 (24\%) of respondents indicated that they had been made fun of for a meal choice in the past, although only $8(3 \%)$ indicated that they altered their food choice at the time as a result.

\subsection{Level of Agreement with Statements Regarding Personal Food Choices}

The level of agreement with statements regarding personal food choices can be seen in Table 1. Levels were rated on a five point Likert-scale and then collapsed into two categories as more and less likely. The overwhelming majority of respondents were comfortable ordering whatever they wanted when in the presence of their friends $(\mathrm{n}=249 ; 97 \%)$. Students were more likely to feel pressure to make a healthy choice than an unhealthy choice ( $\mathrm{n}=116 ; 45.1 \%$ vs. $\mathrm{n}=8131.5 \%$ ). The response pattern to the given statements indicated that for the majority of respondents fear of what friends might say did not stand in their way from ordering what they preferred. A mere $11.3 \%(n=29)$ agreed that they would not choose a healthy option for fear of what their friends would say to them. A total of $19.5 \%(n=50)$ agreed that they would not choose an unhealthy option for fear of what their friends would say to them.

Table 1. Level of Agreement With Statements Regarding Personal Food Choices $(\mathrm{n}=257)$

\begin{tabular}{|c|c|c|}
\hline & $\begin{array}{l}\text { Agreement } \\
\mathrm{n}, \%\end{array}$ & $\begin{array}{l}\text { Disagreement } \\
\mathrm{n}, \%\end{array}$ \\
\hline $\begin{array}{l}\text { "When I'm out with my friends I can feel comfortable ordering anything I want to } \\
\text { eat." }\end{array}$ & $249,97 \%$ & $8,3 \%$ \\
\hline "I feel pressure to make healthy choices when everyone else is." & $116,45.1 \%$ & $141,54.9 \%$ \\
\hline "I feel pressure to make unhealthy choices when everyone else is." & $81,31.5 \%$ & $176,68.5 \%$ \\
\hline I won't choose a healthy option, for fear of what my friends might say to me." & $29,11.3 \%$ & $228,88.7 \%$ \\
\hline $\begin{array}{l}\text { "I won't choose an unhealthy option, for fear of what my friends might say to } \\
\text { me." }\end{array}$ & $50,19.5 \%$ & $207,80.5 \%$ \\
\hline
\end{tabular}

\subsection{Frequency with Which the Respondent Feels Pressure in Making Personal Food Choices}

The frequency with which the respondents feel pressure in making personal food choices is indicated in Table 2. Levels were rated on a five point Likert-scale and then collapsed into two categories as more and less often. Roughly one-fifth of respondents felt pressure in a group setting to order like and to make unhealthy food choices with their friends $(n=54,21 \%)$. Nearly one-third, $(n=73,28.4 \%)$, of respondents felt pressure to make healthy food choices when they were with their friends. A small percentage of respondents $(n=42,16.3 \%)$ felt their friends led them to order something they did not want. This was the case for ordering an acceptable option $(\mathrm{n}=47,18.3 \%)$ and feeling pressure to eat as much food as friends were eating $(\mathrm{n}=53,20.6 \%)$. There were no statistically significant differences between groups. 
Table 2. The frequency with which the respondent feels pressure in making personal food choices $(n=257)$

\begin{tabular}{|c|c|c|}
\hline & $\begin{array}{l}\text { More } \\
\text { Often } \\
\mathrm{n}, \%\end{array}$ & $\begin{array}{l}\text { Less } \\
\text { Often } \\
\text { n, } \%\end{array}$ \\
\hline How often do you feel pressure in a group setting to order like everyone else? & $54,21.0 \%$ & $\begin{array}{l}203, \\
79.0 \%\end{array}$ \\
\hline $\begin{array}{l}\text { How often do you feel pressure to make unhealthy food choices when your friends } \\
\text { are? }\end{array}$ & $54,21.0 \%$ & $\begin{array}{l}203, \\
79.0 \%\end{array}$ \\
\hline How often do you feel pressure to make healthy food choices when your friends are? & $73,28.4 \%$ & $\begin{array}{l}184, \\
71.6 \%\end{array}$ \\
\hline $\begin{array}{l}\text { How often do you feel that your friends have led you to order or eat food that you did } \\
\text { not really want? }\end{array}$ & $42,16.3 \%$ & $\begin{array}{l}215, \\
83.7 \%\end{array}$ \\
\hline $\begin{array}{l}\text { How often have you ordered something you did not want because you thought it was } \\
\text { the more acceptable option? }\end{array}$ & $47,18.3 \%$ & $\begin{array}{l}210, \\
81.7 \%\end{array}$ \\
\hline How often do you feel pressure in a group setting, to eat as much your friends? & $53,20.6 \%$ & $\begin{array}{l}204, \\
79.4 \%\end{array}$ \\
\hline
\end{tabular}

\section{Discussion}

This study offers insight into the role that social influences can have on the food choices of college students. For the most part, students reported being comfortable making decisions about their food in social context. In agreement with findings from other studies, respondents indicated some pressure to consume similar amounts of food when in the presence of others (Brindal, Wilson, Mohr, \& Wittert, 2015; de Castro, 1994; de Castro \& de Castro, 1989; Robinson, Thomas, Aveyard, \& Higgs, 2014). Additionally, respondents were more likely to feel pressured socially to make healthy food choices rather than unhealthy food choices. This pressure was greater when asked if everyone was and seemed lessened when asked specifically about their friends. Other studies have found that social norms do in fact influence healthy choices (Ball, Jeffery, Abbott, McNaughton, \& Crawford, 2010). In fact, social support has been found to be an important predictor of fruit and vegetable consumption (Shaikh, Yaroch, Nebeling, Yeh, \& Resnicow, 2008). A focus group study of European university students yielded similar findings. When making food choices, students were not only influenced by individual and physical factors, but by social factors like friends and peers (Deliens, Clarys, De Bourdeaudhui, \& Deforche, 2014). These students were in varied degree programs.

This study is limited in that it was cross sectional, indicating data collection at a single point in time. In addition, it was limited by self-reported data, a relatively small sample size, and fixed geographic location. Further, the instrument was created for this pilot, and therefore, future studies could benefit from use of a validated instrument. These factors limit the ability to generalize findings. Nevertheless, this pilot study does offer insight into how college students perceive their level of being socially influenced to make particular food choices. Multiple studies reveal that individuals were more likely to be friends with people who shared their same interest, physical behavior patterns, or resemblance (Christakis \& Fowler, 2007; De La Haye, Robins, Mohr, \& Wilson, 2010; Higgs, 2014; Robinson, Thomas, Aveyard, \& Higgs, 2014).

The findings of this pilot investigation identified additional areas for discovery. The study of social influences on food choices is important, and should be expanded to examine in person influences, such as educational influences as well as the influence of technological networks. One study of weight related behaviors in males and females found that those who were had more responsibility for their own food planning prior to college were less likely to feel insecure regarding their food choices (Cluskey \& Grobe, 2009). This study also found that knowledge about healthful food choices and skills related to food preparation were lacking in college students and a lack of intrinsic motivation was noted as an important factor in making positive changes (Cluskey \& Grobe, 2009). Future endeavors will consider these additional areas of influence. Learning more about the impact of social influence on healthy and less healthy food choices in college students can be an effective way to inform developing interventions.

\section{Competing Interests Statement}

The authors declare that there is no conflict of interests regarding the publication of this paper. 


\section{References}

Ball, K., Jeffery, R. W., Abbott, G., McNaughton, S. A., \& Crawford, D. (2010). Is healthy behavior contagious: Associations of social norms with physical activity and healthy eating? Int J Behav Nutr Phys Act, 7(7), 86. http://dx.doi.org/10.1186/1479-5868-7-86

Berger, J., \& Heath, C. (2008). Who drives divergence? Identity-signaling, out-group dissimilarity, and the abandonment of cultural tastes. J Pers Soc Psychol, 95(3), 593-607. http://dx.doi.org/10.1037/0022 $-3514.95 .3 .593$

Berger, J., \& Rand, L. (2008). Shifting signals to help health: Using identity signaling to reduce risky health behaviors. J Cons Res, 35(1), 509-518. http://dx.doi.org/10.1086/587632

Bove, C. F., Sobal, J., \& Rauschenbach, B. S. (2003). Food choices among newly married couples: Convergence, conflict, individualism, and projects. Appetite, 40(1), 25-41. http://dx.doi.org/10.1016/S0195-6663(02) 00147-2

Brindal, E., Wilson, C., Mohr, P., \& Wittert, G. (2015). Eating in groups: Do multiple social influences affect intake in a fast-food restaurant? $J$ Health Psychol, 20(5), 483-9. http://dx.doi.org/10.1177/13591053 15576607

Christakis, N. A., \& Fowler, J. H. (2007). The spread of obesity in a large social network over 32 years. $N$ Engl J Med, 357(4), 370-379. http://dx.doi.org/10.1056/NEJMsa066082

Cluskey, M., \& Grobe, D. (2009). College weight gain and behavior transitions: Male and female differences. $J$ Am Diet Assoc, 109(2), 325-329. http://dx.doi.org/10.1016/j.jada.2008.10.045

de Castro, J. M. (1994). Family and friends produce greater social facilitation of food intake than other companions. Physiol Behav, 56(3), 445-455. http://dx.doi.org/10.1016/0031-9384(94)90286-0

de Castro, J. M., \& de Castro, E. S. (1989). Spontaneous meal patterns of humans: Influence of the presence of other people. Am J Clin Nutr, 50(2), 237-247.

De La Haye, K., Robins, G., Mohr, P., \& Wilson, C. (2010). Obesity-related behaviors in adolescent friendship networks. Social Networks, 32(3), 161-167. http://dx.doi.org/10.1016/j.socnet.2009.09.001

Deliens, T., Clarys, P., De Bourdeaudhui, I., \& Deforche, B. (2014). Determinants of eating behavior in university students: A qualitative study using focus group discussions. BMC Public Health, 14(53), 1-12.

Hardcastle, S. J., Thogersen-Ntoumani, C., \& Chatzisarantis, N. L. D. (2015). Food choice and nutrition: A social psychological Perspective. Nutrients, 7(10), 8712-8715. http://dx.doi.org/10.3390/nu7105424

Higgs, S. (2015). Social norms and their influence on eating behaviours. Appetite, 86(1), 38-44. http://dx.doi.org/10.1016/j.appet.2014.10.021

Lally, P., Martle, N., \& Wardle, J. (2011). Social norms and diet in adolescents. Appetite, 37(3), 623-627. http://dx.doi.org/10.1016/j.appet.2011.07.015

Marathe, A., Pan, Z., \& Apolloni A. (2013). Analysis of friendship network and its role in explaining Obesity. ACM Trans Intell Syst Technol, 4(3), 56. http://dx.doi.org/10.1145/2483669.2483689

Mollen, S., Rimal, R. N., Ruiter, R. A., \& Kok, G. (2013). Healthy and unhealthy social norms and food selection. Findings from a field-experiment. Appetite, 65, 83-9. http://dx.doi.org/10.1016/j.appet.2013.01.020

Robinson, E., \& Field, M. (2015). Awareness of social influence on food intake. An analysis of two experimental studies. Appetite, 85, 165-70. http://dx.doi.org/10.1016/j.appet.2014.11.019

Robinson, E., Fleming, A., \& Higgs, S. (2014). Prompting healthier eating: Comparing the use of health and social norm based messages. Health Psychology, 33(9), 1057-64. http://dx.doi.org/10.1037/a0034213

Robinson, E., Thomas, J., Aveyard, P., \& Higgs, S. (2014). What everyone else is eating: A systematic review and meta-analysis of the effect of informational eating norms on eating behavior. Journal of the Academy of Nutrition and Dietetics, 114(3), 414-29. http://dx.doi.org/10.1016/j.jand.2013.11.009

Shaikh, A. R., Yaroch, A. L., Nebeling, L., Yeh, M. C., \& Resnicow, K. (2008). Psychosocial predictors of fruit and vegetable consumption in adults a review of the literature. Am J Prev Med, 34(6), 535-543. http://dx.doi.org/10.1016/j.amepre.2007.12.028

Spanos, S., Vartanian, L. R., Herman, C. P., \& Polivy, J. (2014). Failure to report social influences on food intake: Lack of awareness or motivated denial? Health Psychol, 33(12), 1487-94. http://dx.doi.org/10. 


\section{7/hea0000008}

Valente, T. W., Fujimoto, K., Chou, C. P., \& Spruijt-Metz, D. (2009). Adolescent affiliations and adiposity: A social network analysis of friendships \& obesity. $J$ Adolesc Health, 45(2), 202-204. http://dx.doi.org/10. 1016/j.jadohealth.2009.01.007

Vartanian, L. R., Spanos, S., Herman, C. P., \& Polivy, J. (2015) Modeling of food intake: A meta-analytic review. Social Influence, 10(3), 119-136. http://dx.doi.org/10.1080/15534510.2015.1008037

Voorhees, C. C., Murray, D., Welk, G., Birnbaum, A., Ribisl, K. M., Johnson, C. C., ... Jobe, J. B. (2005). The role of peer social network factors and physical activity in adolescent girls. Am J Health Behav, 29(2), 183-90. http://dx.doi.org/10. 5993/AJHB.29.2.9

Yamasaki, M., Midzuno, K., \& Aoyama, K. (2007). The effect of food consumption by others on the consumption of food by experimental subjects: The study situation in which the experimenter cannot know how much subjects eat. Japan J Soc Psychol, 23(2), 173-180.

\section{Copyrights}

Copyright for this article is retained by the author(s), with first publication rights granted to the journal.

This is an open-access article distributed under the terms and conditions of the Creative Commons Attribution license (http://creativecommons.org/licenses/by/3.0/). 